brother nor father with son nor mother with daughter, nor would neighbour break bread with neighbour. There was no kindness among us, but misery and unhappiness. In the streets unkindness one to another; at home anguish, seeing children crying for bread and others dying' (' Chronicle of Novgorod,' A.D. I230). In the Irish famine in the middle of the last century Donovan described a father engaging in a life and death struggle with his son for the sake of a potato. Loss of all the normal standards of morality under the impact of undernutrition has been described again and again in history, and there is no reason to suppose it would be any different today.

The population of the world is increasing at an alarming rate. India and China are on the verge of starvation today, and countries such as England, with a population greater than the land can possibly support, may be called upon at any time through war or even through the operation of the normal laws of economics to face a period of undernutrition and perhaps worse. Mankind has the knowledge and ability to prevent all this, but will he do it ? Those horsemen of the Apocalypse are grim figures and they are galloping round the world just as furiously today as they were at the end of the $15^{\text {th }}$ century. They have lived longer than the saints and we can only hope that as they sweep on they will not be allowed to ravage and destroy as they would like to do.

\title{
NEOPLASMS OF THE EXTRA HEPATIC BILE DUCTS
}

\author{
By Andrew M. Desmond, F.R.C.S. \\ Consultant Surgeon, St. Fames's Hospital, Balham
}

The object of this communication is to draw attention to certain neoplasms occurring in the extra-hepatic biliary duct system, and it is based on a small series of cases treated with varying results. The anatomical region involved is shown in Fig. $I$, to which is appended the relative frequency of occurrence at each site as noted by Rolleston and McNee (1929). Neoplasms of the gall bladder itself are not discussed, neither are those tumours referred to as carcinomata of the ampulla of Vater, although there is good evidence to suggest that many of these cancers have their origin in the lower end of the common bile duct. The neoplasms under discussion are frequently very small and localized, and may not be recognized during a laparotomy for obstructive jaundice unless the surgeon is aware of their occurrence.

\section{Anatomical Considerations}

The hepatic ducts issue from the liver and unite to form the common hepatic duct often only a few millimetres from the liver substance, so that neoplasms arising from them involve the liver at an эrly stage and early become inoperable.
The common hepatic duct usually has a separate existence for 2 to $3 \mathrm{~cm}$. before being joined by the cystic duct to form the common bile duct, so that it is possible that a small neoplasm could be excised with restoration of duct continuity. It will be seen (Fig. I) that the greatest proportion of tumours arise at the junction of the cystic and common hepatic ducts and would require at least a cholecystectomy and partial choledochotomy.

The common bile duct is approximately $7 \mathrm{~cm}$. long and consists of an easily accessible supraduodenal portion and a retroduodenal part, which may or may not be embedded in the substance of the pancreatic head. Tumours of the supraduodenal portion could be treated by local excision, but removal of a retroduodenal one would probably necessitate a wedge pancreatectomy or preferably a radical pancreatico-duodenectomy.

The lymphatics of the bile ducts drain into the hepatic glands related to the stem of the hepatic artery and extending into the porta hepatis. The cystic duct lymphatics drain into the cystic gland near the neck of the gall bladder, though this gland may also drain the other biliary channels as 
illustrated in Case 6. Efferents from all these glands pass to the coeliac group.

Histologically the ducts consist of an outer layer of fibro-areolar tissue containing some circular muscle fibres, and an inner mucous membrane of columnar epithelium with lobulated mucous glands.

\section{Pathological Considerations}

These tumours may be benign or malignant.

\section{Benign}

Christopher (1933) collected 4I cases of benign tumour of the extra-hepatic bile ducts from the literature; 16 were papillomata, 15 adenomata, 4 lipomata, 2 fibromata, I neuroma, I granuloma, I melanoma and I carcinoid. He himself reeportd one further adenoma. All the patients were middle aged or over and presented with obstructive jaundice. Cattell and Pyrtek (1950) reported two further papillomata which were successfully treated by transduodenal resection. Below is reported a further personal case of papilloma (Case 8). There seems to be some evidence that these benign tumours are the precursors of the malignant ones, and both types may occur in the same patient (Case 6). Cattell and Pyrtek make a most convincing case for their belief that in four of their cases a carcinoma in the ampullary region arose from an adenoma or papilloma.

\section{Malignant}

It is perhaps fortunate that the occurrence of carcinoma in these narrow bile channels results in the onset of a serious symptom, i.e. jaundice, at an early stage, so that the patient may submit himself for treatment before extensive metastases have developed. If, therefore, it can be shown that these growths are of low malignancy, a local as opposed to a radical resection may suffice with a corresponding lower operative mortality.

Opinion seems to be divided on this point. Dick (1939), reporting I3 cases discovered at autopsy, stated that in II of these there was no. extension outside the duct wall, nor was there any evidence of glandular or other metastases. The tumours were adenocarcinomata with very little anaplasia, the acini being well formed although irregular and with darkly staining nuclei. Mitoses were unusual and the stroma dense. The tumours were small $(0.4$ to $2.0 \mathrm{~cm}$.) and tended to be infiltrative rather than proliferative. They were confined to a small area or extended diffusely over a length of duct $2 \mathrm{~cm}$. or more.

A diametrically opposite view is expressed by Brunschwig (1948) who states that the tumours are commonly anaplastic and very malignant, the prognosis being uniformly bad. Willis (1948) in his series of $\mathrm{I}_{5}$ autopsy cases also found them to be relatively benign and metastases infrequent. 3 Gordon-Taylor (1942), however, described a case $\stackrel{\mathbb{D}}{\stackrel{2}{C}}$ in which he removed a tumour of the lower end $c$. of a very dilated bile duct, but the patient died $\overrightarrow{\vec{F}}$ from metastases in one year.

All these views are, of course, correct, for most carcinomata exist in relatively benign and malignant forms, but the personal experience of any one $\frac{\vec{\sigma}}{\vec{D}}$

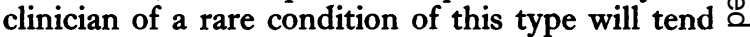
to give him a biased opinion. From a review of $\%$ the literature, however, I have formed the im- $\vec{O}$ pression that the majority are of low malignancy. In the present series also this has been true. $\vec{\omega}$ Unlike carcinomata of the gall bladder, the co- $\frac{}{\circ}$ existence of gall stones in these cases appears to be the exception rather than the rule.

\section{Clinical Manifestations}

The presenting symptom is usually progressive, painless, obstructive jaundice with pale stools and dark urine. There may be a history of flatulent dyspepsia. In two of our cases colicky pain and chills heralded the onset of the jaundice and common bile duct calculus was suspected. The jaundice in the benign lesions may be less progressive and tend to vary, the reason for this being well demonstrated in Fig. 8, which shows how the tumour may act as a ball valve.

Apart from jaundice and perhaps some wasting the only physical sign may be a palpable gall bladder. This will, of course, depend on the position of the lesion. A tumour above the cystico-hepatic junction is associated with a collapsed gall bladder. If at the cystico-hepatic junction the gall bladder will be distended with mucus, if below this point it will be distended with bile or mucus (' white bile').

Radiography is of doubtful value and pathological investigations may confirm the obstructive nature of the jaundice, but are necessary in assessing liver function. The exact diagnosis is thus determined only at laparotomy.

At operation the identification of the lesion is of 을 paramount importance. The duct systems must be brought into view and reliance must not be placed on palpation alone. To facilitate this, a complete Kocher's mobilization of the duodenum os must be carried out. With the assistant gently $N$ holding the duodenum over to the left, an incision $\underset{\omega}{N}$ is made into the peritoneum on the lateral aspect of the duodenum, where apart from a few minute 0 veins, it is bloodless. The fingers are then passed $\overparen{D}$ extraperitoneally behind the duodenum and head $\stackrel{\oplus}{?}$ of pancreas and a bloodless plane of cleavage can be found between the pancreas and the posterior abdominal wall, which extends well over to the left of the duodeno-jejunal flexure. When the 
duodenum and pancreas have been raised forward it will be seen that the peritoneum on the lateral and inferior aspects of the third and fourth parts of the duodenum is also bloodless and that when it is divided the pancreas can be drawn forward and rotated to the left, bringing into view the whole retroduodenal portion of the common bile duct and the ampullary region.

\section{Case Reports}

'The first two cases are very briefly described to demonstrate the hopeless prognosis of carcinoma of the hepatic ducts.

\section{Case I}

R.L., male, aged 65 years. A medical man.

April 1949. Complained of flatulent dyspepsia, anorexia and constipation. During the course of the next few weeks he became increasingly jaundiced.

July i 949. A laparotomy was performed elsewhere and the communicated findings were as follows: " The gall bladder was large but could be emptied easily by pressure. The head of the pancreas was hard but not neoplastic. A diagnosis of chronic pancreatitis was made and cholecystduodenostomy performed.' 'The jaundice failed to clear and in fact deepened.

August 1949. Transferred to St. James's Ilospital.

September I949. Laparotomy. 'There was a large carcinoma of the hepatic ducts which extended well into the liver substance at the porta hepatis. Choledochotomy was performed and a little white bile was extruded. Both hepatic ducts were blocked and could not be dilated. The patient died ten days later.

\section{Case 2}

F.G., male, aged 65 years. A cellarman.

May 1945. Onset of painless progressive jaundice with dark urine and pale stools. The liver was enlarged but smooth and the gall bladder was not palpable. Pathological investigations confirmed the obstructive nature of the jaundice.

June 1945. Laparotomy revealed a collapsed gall bladder and high in the porta hepatis was a malignant mass extending into the liver substance and appearing to arise from the common hepatic duct. Choledochotomy was performed but attempts to dilate the ducts failed. The abdomen was closed.

He was discharged from hospital but died very shortly afterwards.

'The following two cases were unfit for primary resection of the growth and cholecyst-gastrostomy

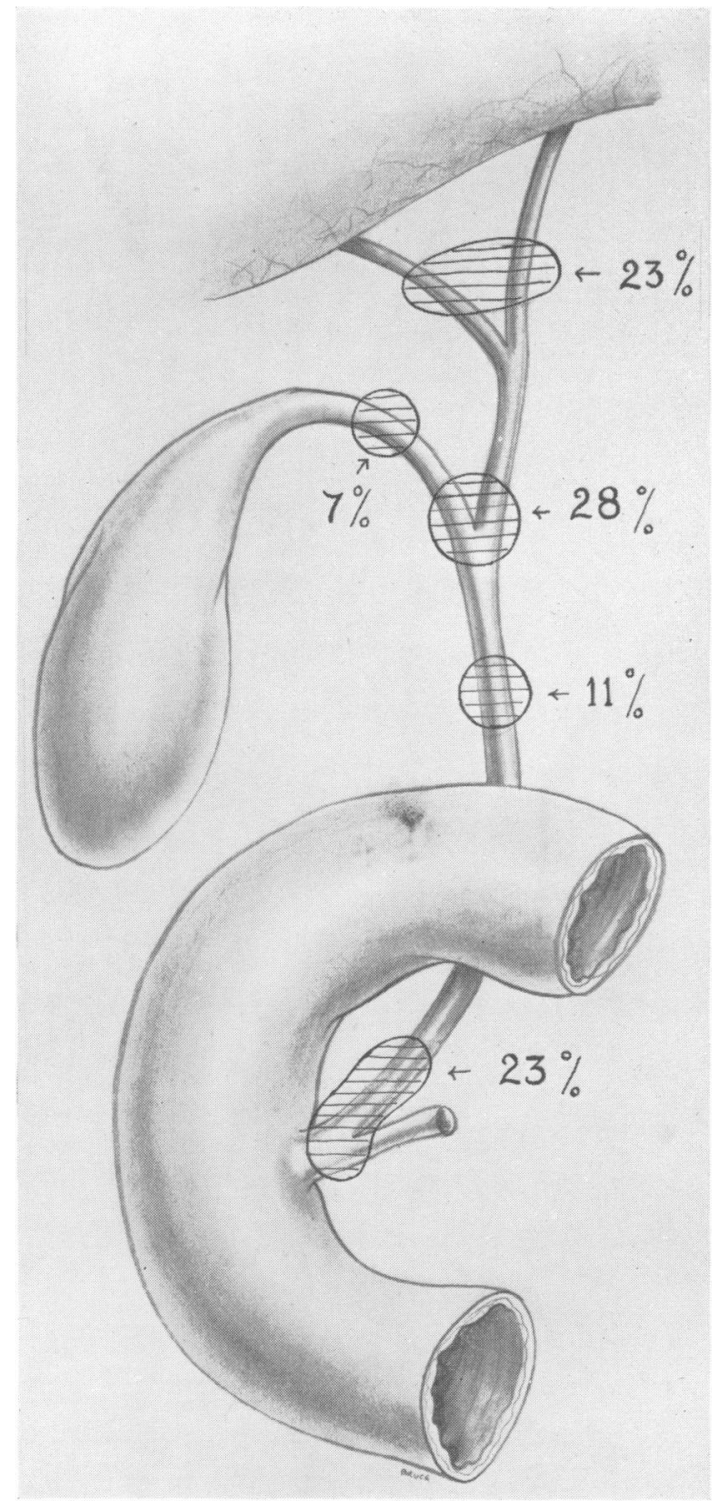

FIG. I.-Diagram of the extrahepatic bile ducts showing the relative frequency of neoplasms occurring within them (Rolleston and McNee, I929).

was performed as a first stage, but both died before the second stage could be performed.

\section{Case 3}

S.C., male, aged 79. A mental defective who had been in a mental institution for many years. June i950. 'Transferred to St. James's Hospital. For ten weeks progressive painless jaundice and loss of weight. 


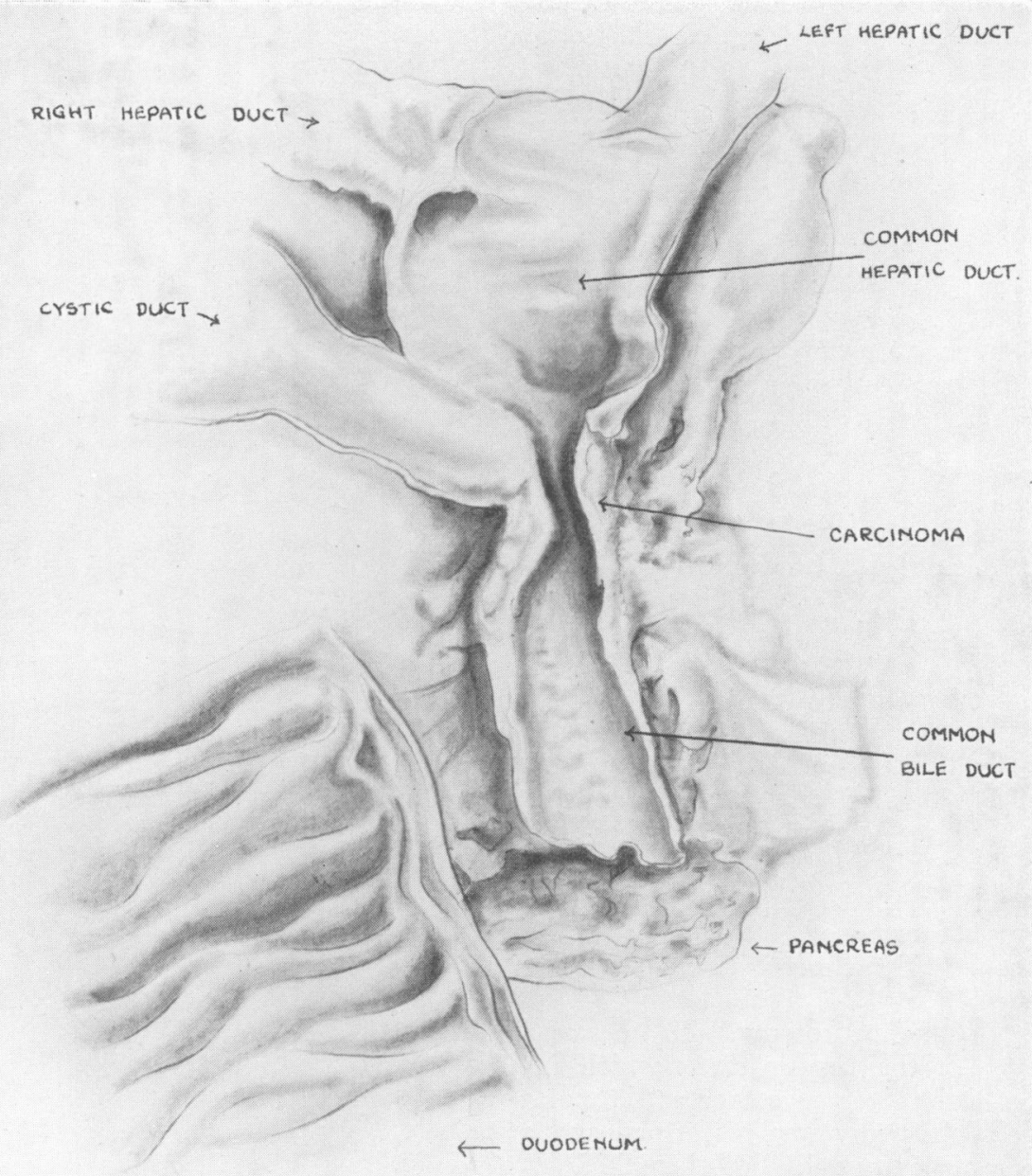

FIG. 2.-Carcinoma just below the cystico-hepatic junction (Case 3).

On examination a feeble mentally defective old man, deeply jaundiced. Abdomen revealed a large smooth liver and a palpable gall bladder. Pathological investigations confirmed the obstructive nature of the jaundice and demonstrated poor liver function. After a course of vitamin $K$ and intravenous protein replacement a laparotomy was performed under general anaesthesia. The gall bladder was distended with white bile. There were no stones. The common hepatic duct was grossly dilated. There was a carcinoma of the supra-pancreatic portion of the common bile duct extending up to the cystico-hepatic junction. A cholecyst-gastrc stomy was performed.

Post-operatively the patient progressed well for a few days, but suppression of urine supervened and he died on the tenth day. The findings at autopsy are shown in Fig. 2. There was no evidence of glandular or other metastases. The microscopic section showed a well-differentiated adenocarcinoma of the bile duct extending out- $\mathrm{O}$ wards to, but not involving, the head of the pancreas.

\section{Case 4}

D.R., male, aged 86. A mental defective who $\mathrm{N}$ had been in an institution for many years.

June 1950. Transferred to St. James's Hospital. April 1950. He had a sudden attack of abdominal pain, vomiting and chills. He had be- $\frac{\tau}{\Phi}$ come progressively weaker since this time and for $\stackrel{?}{+}$ four weeks had become progressively more $\square$ jaundiced with pale stools and dark urine. He had ${ }_{\vec{P}}$ no further attacks of pain but had lost weight.

On examination. A feeble old man with severe $\frac{\vec{Q}}{\mathbb{Q}}$ chronic bronchitis and emphysema. He was 


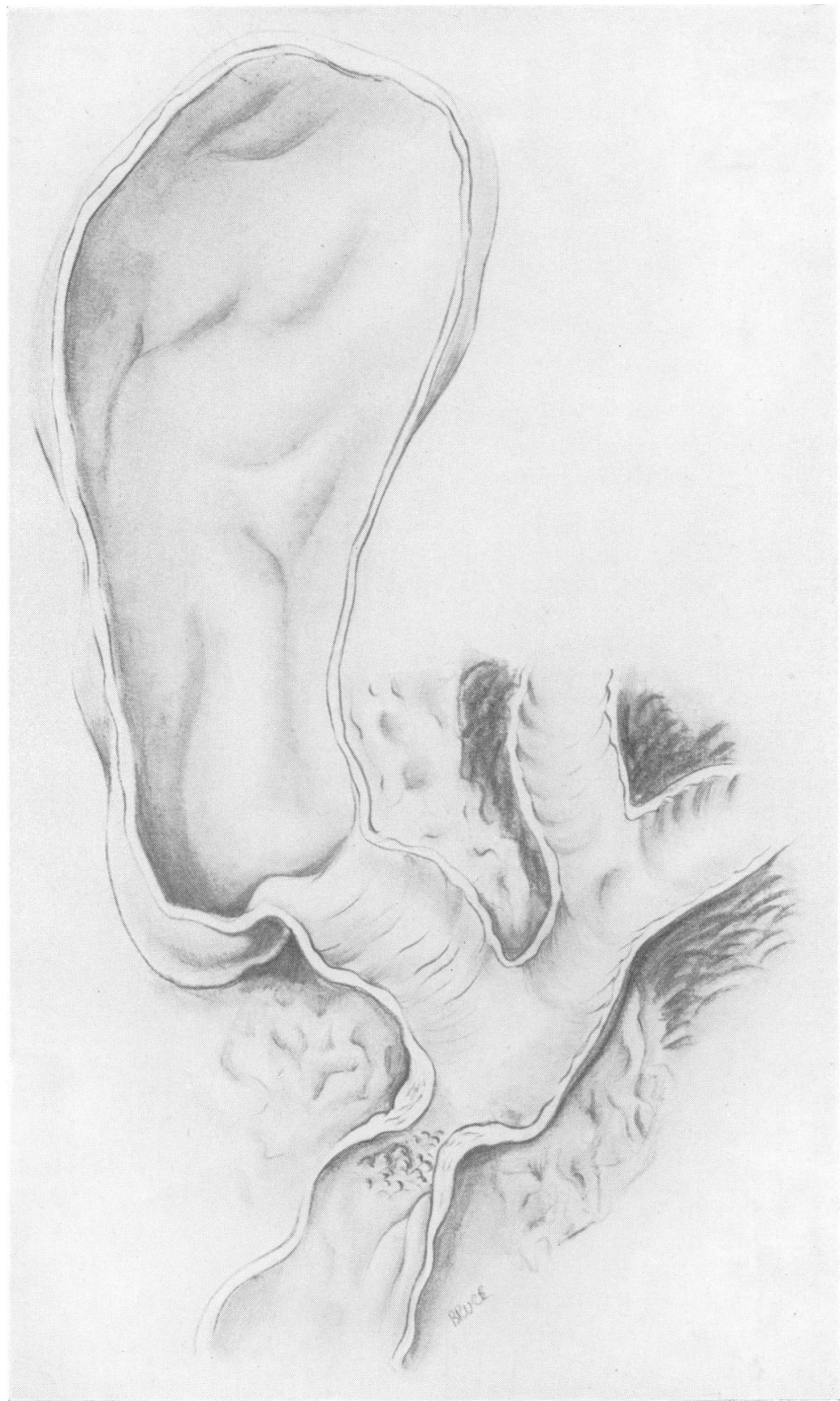

deeply jaundiced. 'The abdomen was somewhat distended and there was some free fluid. The liver was palpable but the gall bladder could not be felt. Investigations confirmed the obstructive nature of the jaundice and demonstrated poor liver function.

After a course of vitamin $K$ and intravenous protein replacement a laparotomy was carried out 


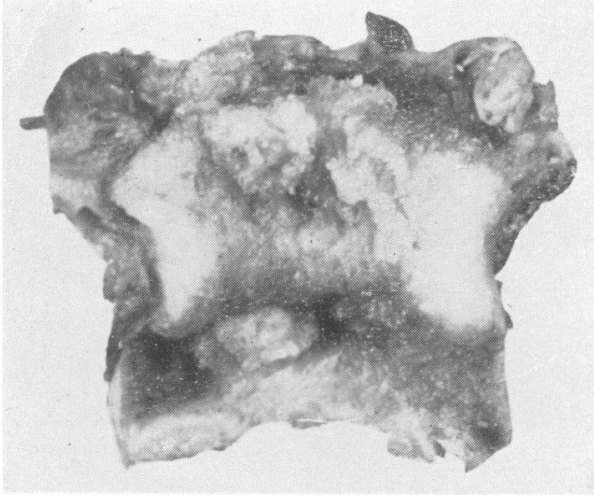

Fig. +.- Excised portion of common bile duct ( $x 2 !)$ containing a carcinoma from Case 5 .

under local anaesthesia. 'I'here was some straw coloured free fluid in the peritoneal cavity. 'The gall bladder was enlarged and tensely distended with clear mucus. There werc no stones. A hard tumour was felt in the region of the head of the pancreas but the patient's general condition precluded a more extensive search. A cholecystgastrostomy was performed and the wound closed.

Following operation he had suppression of urine and became comatose after 48 hours and died on the third post-operative day. The findings at autopsy are shown in Fig. 3. There was no evidence of glandular or other metastases. The microscopic section showed a well-differentiated adenocarcinoma of the bile duct with local invasion of the pancreas over a small area.

\section{Case 5}

A successful local resection of a carcinoma of the infraduodenal duct.

M.K., a female, aged 6o, was admitted in January I 950 with jaundice. For several months she had complained of epigastric discomfort a few minutes after meals, made worse by fatty foods. There had been some loss of weight. Six weeks previously she had had an attack of shivering and pain in the right subcostal region. For four weeks she had become increasingly jaundiced with pale stools and dark urine.

On examination she was deeply jaundiced but nutrition was good. The abdomen was obese and the liver palpable and tender, but the gall bladder was not felt. Pathological investigations confirmed the obstructive nature of the jaundice and revealed normal liver function.

After a course of vitamin $\mathrm{K}$ a laparotomy was performed. The gall bladder was enlarged and tensely distended by a mixture of mucus and bile, and contained one stone. The suprapancreatic

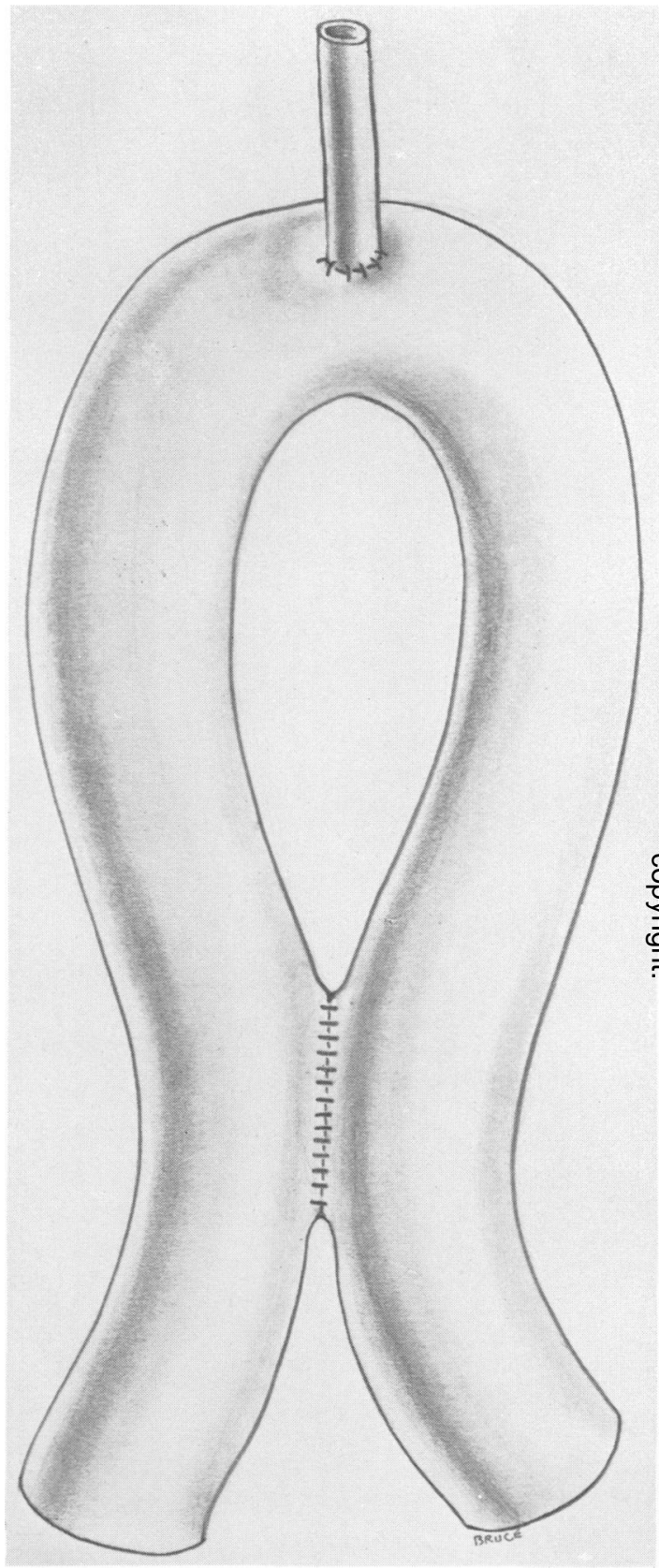

FIG. 5.-End in side choledocho-jejunostomy with lateral entero-enterostomy.

bile ducts were grossly dilated. The head of the pancreas was palpably normal. The duodenum and pancreatic head were freely mobilized and a carcinoma of the bile duct about $2.5 \mathrm{~cm}$. from the ampulla was found. The pancreas was not in- 


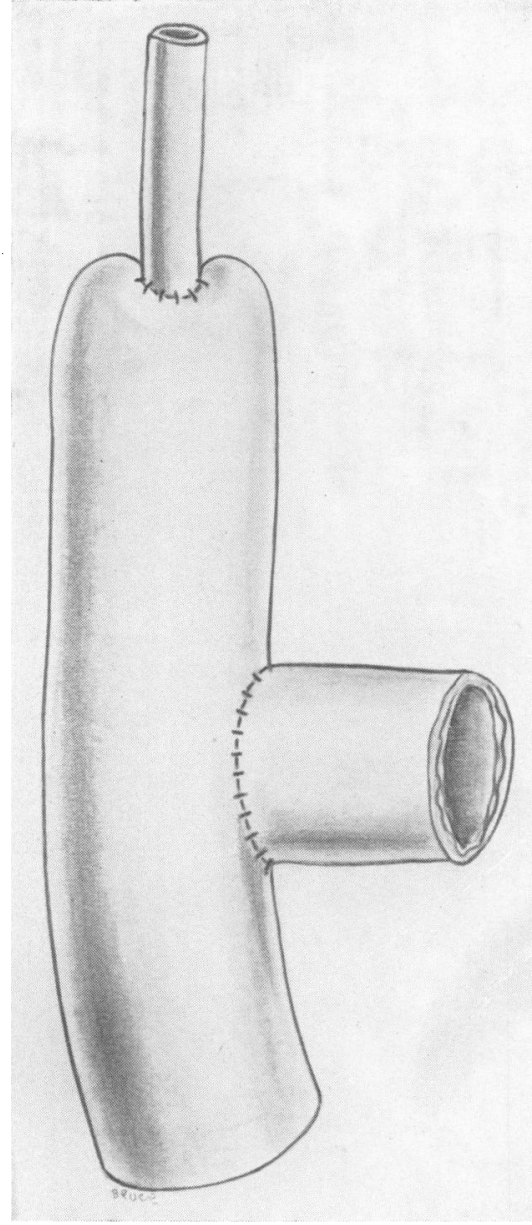

Fig. 6.- End to end choledochojejunostomy with entero-anastomosis en Roux.

volved and there were no metastases. 'The bile duct was easily freed from both duodenum and pancreas, some brisk haemorrhage being controlled by suture. A portion of the bile duct about $2.5 \mathrm{~cm}$. long containing the growth was resected (Fig. 4). The distal duct was ligated and an end-in-side choledocho-jejunostomy was performed over a tube. A wide lateral anastomosis between the two jejunal loops was made (Fig. 5), and the operation completed by performing a cholecystostomy and removing the gall stone. Rutherford-Morrison's pouch was drained through a stab wound.

Convalescence was uneventful and the patient was discharged one month later. Microscopic section showed a well-differentiated adenocarcinoma confined to the bile duct.
In April an X-ray showed that the tube had passed although the patient had no knowledge of this. At the follow-up in January r $95^{I}$ she was well and had put on weight, and there was no evidence of recurrence.

In Case 6 a primary resection was performed but the patient developed suppression of urine and died.

C.T., aged 68 , a medical man, was admitted in August 1950 with painless jaundice.

He was transferred from another hospital with a vague history of nausea and anorexia for a few weeks followed by the gradual development of jaundice. There had been considerable weight loss. 'The stools were pale and the urine dark.

On examination he was thin and jaundiced. His mental state was peculiar, with an intense cancerophobia, and he constantly threatened to take his own life. 'The gall bladder was easily palpable. Pathological investigations confirmed the obstruc-

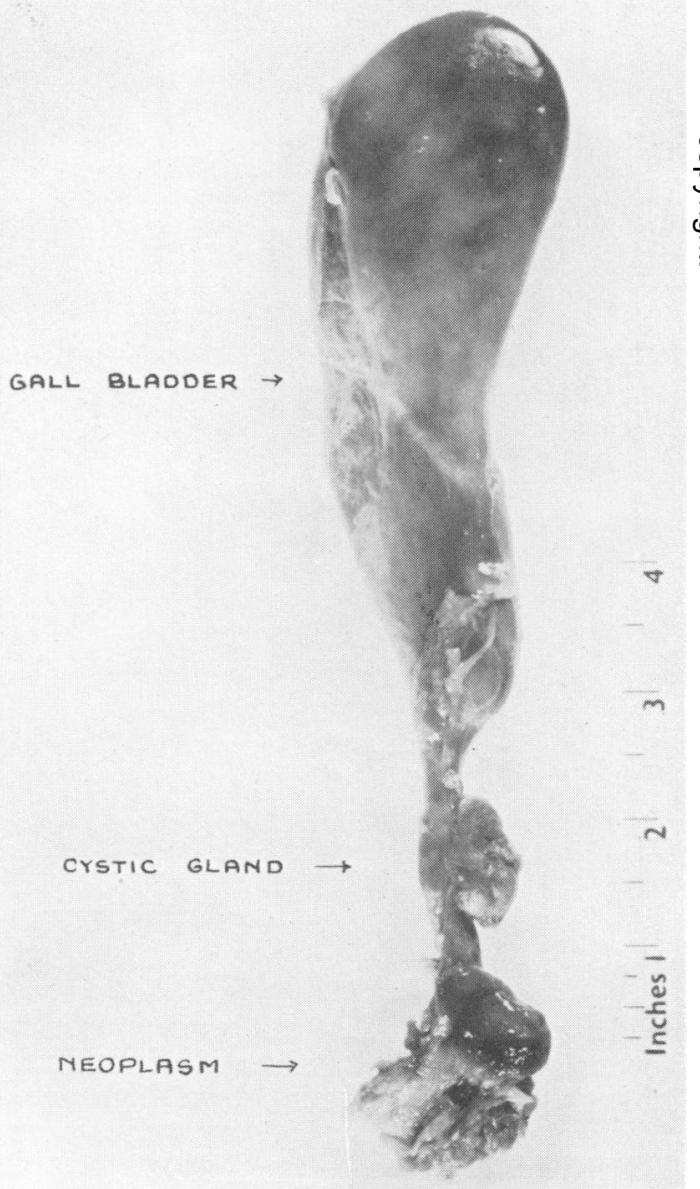

Fig. 7.- Resected specimen from Case 6. 


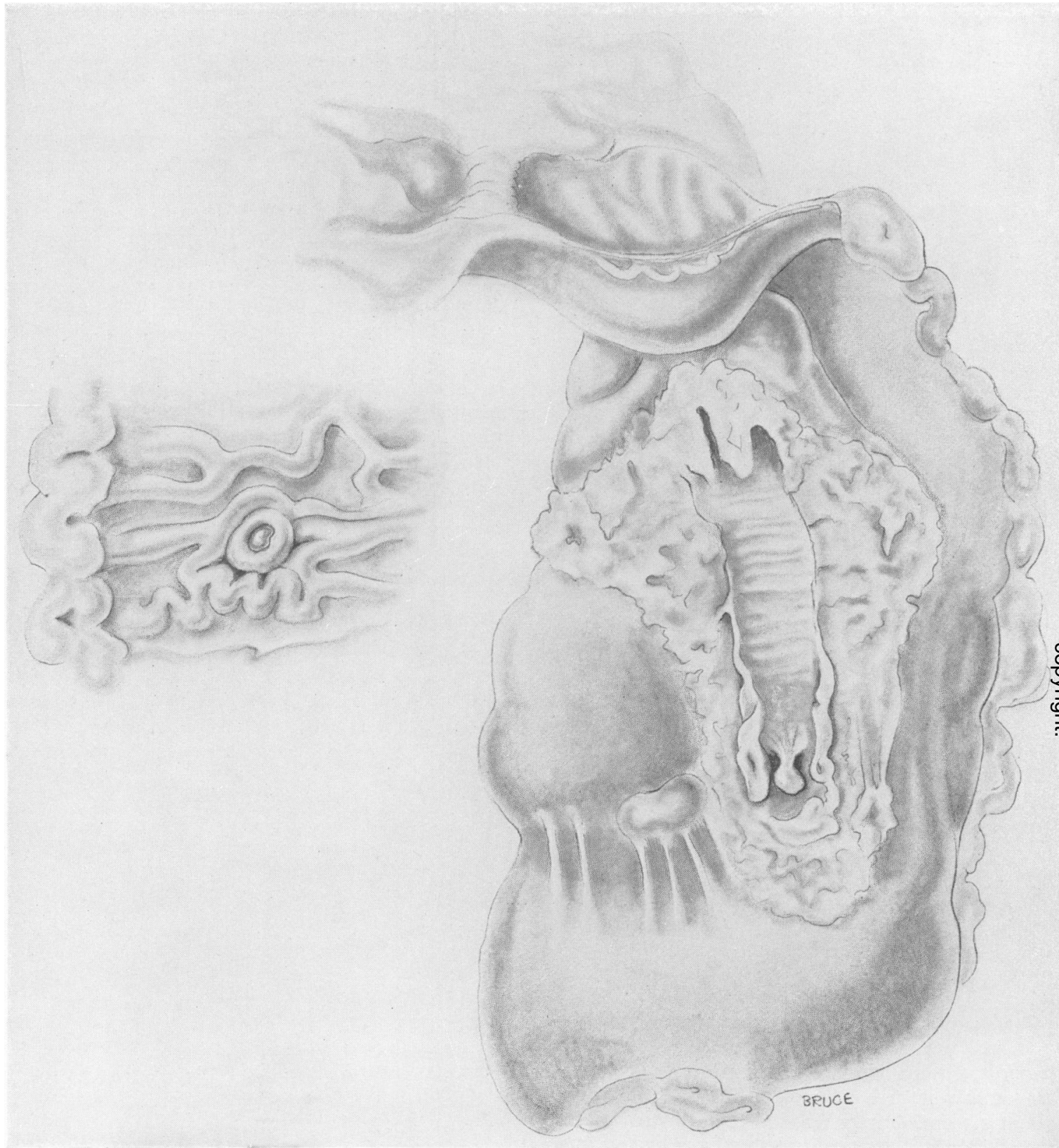

Fig. 8.-Artist's impression of resected specimen from Case 8 .

tive nature of the jaundice and revealed poor liver function. Barium meal was essentially normal.

After a course of vitamin $\mathrm{K}$ and high protein and carbohydrate diet a laparotomy was performed. The gall bladder was enlarged and tensely distended with a mixture of bile and mucus. A mass was felt in the region of the lower end of the bile duct and the duodenum and pancreas were freely mobilized, revealing a carcinoma of the lower end of the common bile duct. The cystic gland was enlarged and hard. The gall bladder, cystic gland, cystic duct and lower part of the common hepatic duct were mobilized and removed with the whole common bile duct and a wedge of pancreas ob- 
viously involved by growth. Brisk pancreatic haemorrhage was controlled by suture. An end-to-end choledocho-jejunostomy was made and the proximal jejunum anastomosed end-in-side to the distal (Roux) (Fig. 6).

The resected specimen is shown in Fig. 7. The microscopic section showed a well-differentiated adenocarcinoma of the common bile duct. There was a dense fibrous stroma. The carcinoma had spread beyond the confines of the duct wall to involve the head of the pancreas over a small area. In Hartmann's pouch was a benign papilloma. The cystic gland contained secondary deposits.

Following operation the patient developed complete suppression of urine and in spite of all treatment died on the fourth day. Autopsy revealed no evidence of metastases.

The prognosis in these cases is difficult to assess as there are very few reports in the literature of successful resections followed up for a long period. The following case throws some light on this problem as she died from recurrence fou $r$ years after local resection. The growth was more extensive and a pancreatico-duodenectomy might have resulted in a happier outcome. The long survival, however, does illustrate the relatively benign nature of some of the growths.

\section{Case 7}

A.L., a female, aged 56 , was admitted in July I94I with painless progressive jaundice of two weeks' duration, with pale stools and dark urine. The gall bladder was palpable. Pathological investigations confirmed the obstructive nature of the jaundice and revealed good liver function.

After a preliminary course of vitamin $K$ a laparotomy was performed. The gall bladder was enlarged and tensely distended with clear bile. There was a small mass in the head of the pancreas. A first stage cholecyst-gastrostomy was performed.

The jaundice cleared up and one month later the abdomen was re-opened. Mobilization of the duodenum and pancreatic head revealed a carcinoma of the lower end of the bile duct involving the head of the pancreas and the duodenal wall. A wedge of tissue consisting of a portion of pancreas, the common bile duct, a section of the duodenal wall and one hepatic lymphatic gland was removed. The duodenum was sutured and the proximal end of the bile duct ligated. Postoperatively a pancreatic fistula developed, which drained for five weeks and then healed.

Microscopic section showed a well-differentiated adenocarcinoma of the bile duct involving pancreas and duodenum. Resection appeared to be well clear of the growth. 'I'he gland contained metastases.

The patient remained well until February 1945 when she began to lose weight. She then developed gross steatorrhoea and osteoporosis, and died in June 1945. At post-mortem there was a recurrent growth in the pancreatic head and metastases in the liver and kidneys.

The last case is the report of a successful pancreatic resection for a papilloma of the ampulla of Vater.

\section{Case 8}

W.A., a male, aged $6 \mathrm{r}$, an estate agent, was admitted in July $195^{\circ}$ with a history of four weeks flatulent dyspepsia, increasing jaundice, pale stools and dark urine.

Examination showed a deeply jaundiced man. The gall bladder was palpable. Pathological investigations confirmed the obstructive nature of the jaundice and revealed good liver function. After a preliminary course of vitamin $\mathrm{K}$ a laparotomy was performed. It was noticed on the morning of the day of operation that the jaundice was beginning to fade.

The gall bladder and common bile duct were not dilated. A hard, small tumour was felt in the region of the ampulla of Vater and was considered to be an early carcinoma. A pancreatico-duodenectomy was performed, the duodeno-jejunal ? flexure not being removed. An end-in-side choledocho-jejunostomy over a tube and a gastrojejunostomy were made. A safety valve cholecystostomy was performed. The pancreatic stump was oversewn and embedded. The wound was closed with drainage; bile drained for 12 days but the fistula then closed. $\mathrm{He}$ then developed a pancreatic fistula which was treated by continuous suction, and eventually closed in about four weeks. The patient was discharged well after two months in hospital and returned to work one month later. $\mathrm{He}$ has remained well and his nutrition remains good with pancreatin; although the stools are bulky and fatty, there is no diarrhoea.

An artist's impression of the resected specimen is shown in Fig. 8.

The papilloma was I $\mathrm{cm}$. long and its distal part $3 \mathrm{~mm}$. diameter. Its long stalk and some laxity of the mucous membrane to which it was attached suggest that attempts were being made to extrude it.

The microscopic section showed a simple papilloma of the bile duct and there was no epithelial hyperplasia. Serial sections failed to show the structure of the stalk or base.

One must admit that a radical operation was unnecessary in this case. The correct procedure should have been to open the duodenum and in- 
spect the ampulla when a local diathermy excision of the polyp could have been carried out as advised by Cattell (Cattell and Pyrtek, 1950).

\section{Cornmentary}

I feel that the brief reports of these eight cases offer their own lessons, but would like to summarize shortly my own opinions.

In a case of obstructive jaundice in which there is some doubt as to the cause at laparotomy:

I. When the gall bladder is collapsed a careful dissection in the porta hepatis may reveal a growth. Usually little can be done but I would suggest that by opening the duct below and dilating the malignant stricture, palliation may be achieved with temporary clearance of the jaundice.

2. When the gall bladder is distended the duodenum and head of pancreas should be freely mobilized and the bile duct brought under direct vision. If there is a growth and it is absolutely confined to the bile duct a local resection is advised. If it appears to have spread outside the confines of the duct and involved the pancreatic head, a pancreatico-duodenectomy should be performed.

3. Where a lesion of the ampulla is suspected and there is the slightest doubt as to its nature, a transduodenal inspection should be made after mobilizing the duodenum. If doubt still exists, and facilities for frozen sections are available, a diathermy excision should be performed and the treatment will be dependent on the pathological repori.

Having performed a resection of one sort or another, the bile duct should be anastomosed to the jejunum, and this is much easier to perform over a soft rubber tube. The portion of jejunum should always be defunctioned (Figs. 5 and 6 ) to obviate the danger of ascending cholangitis. I have found that ligation of the proximal end of the duct and usage of the gall bladder to re-establish biliary continuity is unsatisfactory, the danger being that the bile duct will slough and the patient succumb to a biliary peritonitis.

The decision to perform a one- or two-stage operation depends upon the age and general condition of the patient. A one-stage operation is preferable but when the liver function is demonstrably poor a two-stage procedure is necessary. We have found that the most useful liver function tests are serum protein, thymol turbidity and alkaline phosphatase estimations.

In conclusion I would like to say that although these are relatively rare tumours they are as common as carcinoma of the gall bladder and as carcinoma of the pancreas (Willis, I948). Their identification may often mean the saving of life by a relatively simple surgical procedure.

I am grateful to Mr. Norman C. Tanner for giving me access to his notes, and to Mrs. Mace and Miss Mason of the photographic department of St. James's Hospital.

\title{
BIBLIOGRAPHY
}

BRUNSCHWIG, A. (1948), Y.A.M.A., 136, 28.

GORDON-TAYLOR, G. (1942), Brit. Med. F., ii, I 19.

CAT'TELL, R. B., and PYRTEK, L. J. (1950), Surg. Gy'n. \& Obst., 90, 21.

('HRISTOPHER, F. (1933), Surg. Gyn. E Obst., 56, 202.

IICK, J. C. (r939), Brit. . . Surg., 26, 757.

ROLLESTON, and MCNEE (1920). "Diseases of Liver, Gall Bladder and Bile Ducts,' MacMillan, London.

WILLIS, R. A. (1948), 'Pathology of Tumours,' Butterworth, I.ondion.

\section{ATOM BOMBS AND RADIATION INJURIES*}

\author{
By Surgeon Commander G. D. Wedd, R.N., Surgeon Commander D. A. Hovenden, R.N., and \\ Instructor Lieutenant A. J. Alabaster, R.N. \\ Royal Nary Medical School, Alverstoke
}

The story of Hiroshima and Nagasaki is now ancient history. It is well known that the two atomic bombs killed about 100,000 people and injured as many more, besides producing untold material damage. Of those who were killed about

* Part of this article has been taken from 'Some Medical Aspects of Atomic Warfare,' G. D. Wedd, Public Health, June i 950.
So per cent. died from burning or from mechanical injuries due to blast damage, which are the normal accompaniments of any explosion. There remained a smaller number, variously estimated at from 10 to 20 per cent., who were uninjured or trivially injured at the time, but who died days or weeks later from the effects of radioactivity.

Radioactivity then is a relatively minor cause of 